\title{
Mass Spectra and Relative Sensitivities of Some Polyphenyls
}

\author{
Paul Bradt and Fred L. Mohler
}

\begin{abstract}
Mass spectra have been measured by evaporating polyphenyls from a tube furnace into the ionization chamber of a $60^{\circ}$ mass spectrometer operated at constant ion accelerating voltage. Mass spectra of pure tetraphenyl, hexaphenyl, and octaphenyl are reported. A synthetic mixture of terphenyl, tetraphenyl, pentaphenyl, hexaphenyl, and octaphenyl in known proportions was evaporated as the temperature was increased step by step from $125^{\circ}$ to $290^{\circ} \mathrm{C}$ and time integrals of the five molecule ion currents were recorded over the time required to completely evaporate the sample. The relative sensitivity increases rapidly with increasing molecular weight.
\end{abstract}

\section{Introduction}

The Mass Spectrometry Section has published several papers on detection and analysis of heavy molecules evaporated from a vacuum-tube furnace directly into the ionization chamber of a mass spectrometer $[1,2,3,4]{ }^{1}$ Mixtures of heavy molecules have been studied by recording the spectra as the temperature is increased step by step. This affords the advantage that the mixture is fractionated in the process of evaporation and the complexity of the mass spectra is reduced. However, the results are qualitative as the abundance of the ions from a given compound will depend both on the amount of the compound in the sample and on the temperature of evaporation. A quantitative measure of the relative abundance of the compounds requires a time integral of the ion current over the time required to completely evaporate the compound from the sample.

At the Bureau there has been interest in the analysis of mixtures of polyphenyls formed when biphenyl is irradiated by neutrons and gamma rays in a high flux reactor. As a basis for analysis of these mixtures, R. L. Alexander of the Engine Fuel Section has supplied us with $m$-terphenyl, $m$-tetraphenyl, $m$-pentaphenyl, $m$-hexaphenyl, and $m$-octaphenyl. He also supplied us with a mixture containing the five polyphenyls in known proportions.

\section{Experimental Procedure}

Mass spectra were measured with a $60^{\circ}$ mass spectrometer of 6 -in. radius of curvature and the spectrum was scanned by varying the magnetic field with a constant electric field of $1,100 \mathrm{v}$. The repeller electrode of the ionization chamber was a fine wire gauze that allowed free entry of the vapor from a tube furnace. The synthetic sample was in a copper tube which extended to within about $5 \mathrm{~mm}$ of the gauze and this was in a 6-mm Pyrex tube which fitted into the entrance port of the ionization chamber. A thermocouple attached to the copper tube recorded the temperature of the sample.

The ionization chamber block attained a temperature of about $190^{\circ} \mathrm{C}$ from heat from the cathode and

\footnotetext{
${ }^{1}$ Figures in brackets indicate the literature references at the end of this paper.
}

the sample tube reached a temperature of $131^{\circ}$ without external heating. Heating the sample tube in turn raised the temperature of the ionization chamber by an amount that was not measured but results indicated that there was no condensation of material in the ionization chamber with the sample at $290^{\circ} \mathrm{C}$. In other experiments the sample holder was further from the ionization chamber and the initial temperature was less than $131^{\circ} \mathrm{C}$.

\section{Results}

Table 1 lists some of the larger peaks in the mass spectra of $m$-tetraphenvl, $m$-hexaphenyl, and $m$ octaphenyl. A striking feature of the spectra is that

TABLE 1. Mass spectra of tetraphenyl, hexaphenyl, and octaphenyl

\begin{tabular}{|c|c|c|c|}
\hline $\mathrm{m} / \mathrm{e}$ & Tetraphenyl & Hexaphenyl & Octaphenyl \\
\hline $\begin{array}{c}77 \\
91 \\
128 \\
152 \\
306^{++}\end{array}$ & $\begin{array}{r}{ }^{\circ} \mathrm{C} \\
126 \\
1.0 \\
0.3 \\
1.2 \\
14.8\end{array}$ & $\begin{array}{c}{ }^{\circ} \mathrm{C} \\
168 \\
1.0 \\
0.7 \\
.64 \\
2.5 \\
1.3\end{array}$ & $\begin{array}{c}{ }^{\circ} \mathrm{C} \\
265 \\
0.2 \\
\quad .19 \\
.11\end{array}$ \\
\hline $\begin{array}{l}165 \\
178 \\
189 \\
202 \\
215\end{array}$ & $\begin{array}{l}\text { 1. } 1 \\
0.8 \\
\text { 1. } 4 \\
\text { 3. } 0 \\
1.15\end{array}$ & $\begin{array}{r}1.4 \\
0.6 \\
.9 \\
1.6\end{array}$ & $\begin{array}{l}.4 \\
.4 \\
.3 \\
.2\end{array}$ \\
\hline $\begin{array}{l}226 \\
228\end{array}$ & $\begin{array}{l}5.3 \\
5.4\end{array}$ & - & .7 \\
\hline $\begin{array}{l}\text { the } \\
239 \\
252\end{array}$ & $\begin{array}{l}0.9 \\
1.2\end{array}$ & $\begin{array}{r}20.7 \\
1.1 \\
1.3\end{array}$ & $\begin{array}{l}.2 \\
.4\end{array}$ \\
\hline $\begin{array}{l}265 \\
276 \\
289 \\
302 \\
610^{++}\end{array}$ & $\begin{array}{l}0.9 \\
3.0 \\
6.3 \\
4.6\end{array}$ & $\begin{array}{l}1.3 \\
2.2 \\
4.4\end{array}$ & $\begin{array}{r}.5 \\
.5 \\
1.1 \\
2.3\end{array}$ \\
\hline $\begin{array}{l}306 \\
320 \\
350 \\
365 \\
380\end{array}$ & $\begin{array}{c}100 \\
\end{array}$ & $\begin{array}{l}3.5 \\
1.1 \\
0.9 \\
2.3 \\
1.2\end{array}$ & $\begin{array}{l}0.22 \\
.3 \\
.4 \\
.5\end{array}$ \\
\hline $\begin{array}{l}441 \\
458 \\
517 \\
532 \\
579\end{array}$ & - & $100^{2.3}$ & $\begin{array}{l}.4 \\
.4 \\
.3 \\
.2 \\
.3\end{array}$ \\
\hline $\begin{array}{l}593 \\
610\end{array}$ & & & $100^{.7}$ \\
\hline
\end{tabular}


all fragment ion peaks are small and get progressively smaller as the molecular weight increases. Fragmentation involving breaking bonds between phenyl rings is negligible and most of the fragment ions involve breaking one of the rings. Spectra of terphenyl and pentaphenyl have been recorded with a $180^{\circ}$ mass spectrometer with a heated reservoir and inlet manifold [5]. All the spectra show that the molecule ion peaks can be used without any correction for interference to analyze a mixture of polyphenyls.

The synthetic mixture contained 23.4-mole percent terphenyl, 21.6-percent tetraphenyl, 17.6-percent pentaphenyl, 22.7-percent hexaphenyl, and 14.7percent octaphenyl. A drop of molten material estimated to be about half a cubic millimeter was placed in the sample holder. This sample was completely evaporated into the ionization chamber over a period of $27 \mathrm{hr}$ and the time integrals of the molecule ion currents were recorded. Only the molecule ion peaks were recorded and only two molecules contributed measurably to the spectrum at any one time. Readings on two peaks could be repeated within about 5 min. The temperature of the sample was increased by small steps to maintain an easily measured rate of change.

Figure 1 is a plot of the ion currents for the five molecule ions (designated $\phi_{3}, \phi_{4}, \phi_{5}, \phi_{6}$, and $\phi_{8}$ ) as a function of time. Upward inflections of the curves mark the times when the temperature was increased. The mass spectrometer filament was turned on at $2: 20$ P. M. and at 3 P. м. the terpehnyl and tetraphenyl ion currents began to rapidly rise to sharp maxima. Heating of the tube furnace began at $7: 30 \mathrm{P}$. м. and over a period of $6 \mathrm{hr}$ the spectrum showed predominantly pentaphenyl with temperatures ranging from $162^{\circ}$ to $174^{\circ} \mathrm{C}$. The hexaphenyl evaporated from $187^{\circ}$ to $214^{\circ} \mathrm{C}$ and the octaphenyl was predominant from $250^{\circ}$ to $287^{\circ} \mathrm{C}$. There was no visible residue left in the sample holder.

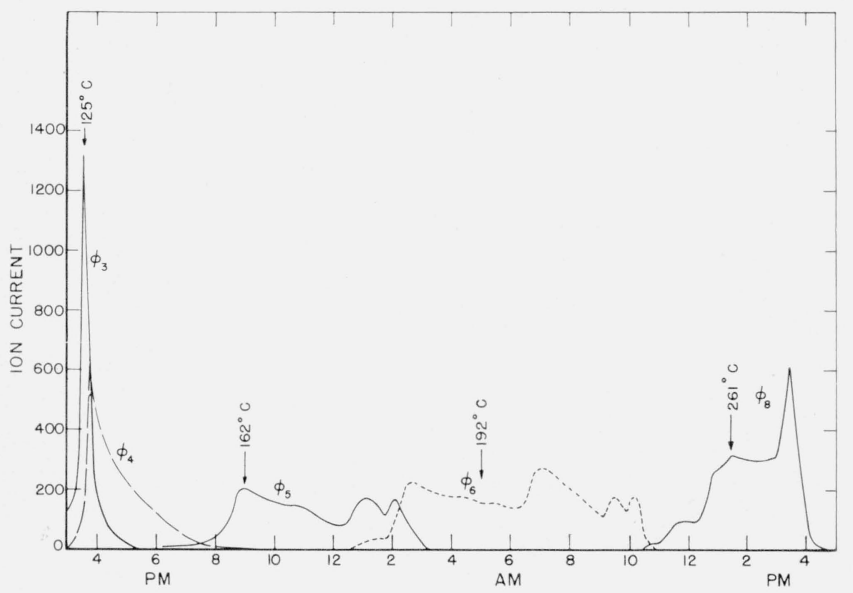

FiguRE 1. Ion currents from a mixture of five polyphenyl molecules as a function of time.

$\phi_{3}, \phi_{4}$ etc., designate the molecule ions. The temperature of evaporation at various times is also indicated.
The rate of evaporation of the terphenyl was so rapid that there is some doubt as to the accuracy of the time integral. For the other compounds the rate of evaporation stayed within a measurable range. Table 2 gives the results. Column 3 gives the time integrals in units of current in arbitrary scale divisions and time in minutes. Column 4 gives the composition of the synthetic mixture in mole percent and column 5 is proportional to the time integrals of column 3 divided by the mole percent abundance of the compound of column 4 .

TABLE 2. Relative sensitivity of polyphenyl molecule ions

\begin{tabular}{|c|c|c|c|c|c|c|}
\hline Molecule & $\mathrm{m} / \mathrm{e}$ & $\begin{array}{l}\text { Integral of } \\
\text { ion current }\end{array}$ & $\begin{array}{l}\text { Mole } \\
\text { per- } \\
\text { cent }\end{array}$ & $\begin{array}{l}\text { Rela- } \\
\text { tive } \\
\text { sensi- } \\
\text { tivity }\end{array}$ & $\begin{array}{l}\text { Isotope } \\
\text { correct }\end{array}$ & $\begin{array}{l}\text { Mono- } \\
\text { isotopic } \\
\text { sensi- } \\
\text { tivity }\end{array}$ \\
\hline Terphenyl_.. & 230 & $3.08 \times 10^{4}$ & 23.4 & 1.0 & 1. 22 & 1.0 \\
\hline Tetraphenyl & 306 & 4. 91 & 21.6 & 1. 74 & 1. 31 & 1.87 \\
\hline Pentaphenyl & 382 & 5. 97 & 17. 6 & 2.58 & 1. 41 & 2.98 \\
\hline Hexaphenyl. & 458 & 9.83 & 22.7 & 3.27 & 1. 50 & 4. 02 \\
\hline Octaphenyl & 610 & 7.95 & 14.7 & 4.09 & 1. 72 & 5. 76 \\
\hline
\end{tabular}

The results show that the sensitivity increases rapidly with increasing molecular weight. The experiment was not designed to give sensitivity in absolute units. The long series of observations was made by one observer and the experiment was not repeated because of the exceptional physical effort involved. Figure 1 indicates that the time schedule of increasing the temperature could be improved.

\section{Discussion}

There are extensive data in the API Catalog of mass spectral data on heavy hydrocarbons obtained with $180^{\circ}$ Consolidated mass spectrometers using a heated reservoir and inlet system held at a temperature sufficient to vaporize the sample completely. Data commonly include sensitivity of the maximum peak of the compound relative to the molecule ion of $n$-hexadecane. These data are not comparable with data obtained in this work and indeed it is difficult to intercompare the published spectra when there are large differences in the molecular weights of the base peaks. This is because the Consolidated mass spectrometer records the spectrum at a constant magnetic field and a variable ion accelerating voltage, and there is a decrease in sensitivity with increasing molecular weight. In this research the ion accelerating voltage was held at a constant value.

The polyphenyls afford an excellent opportunity to study the variation in sensitivity with molecular weight, as the molecule ions are by far the largest peaks and other characteristics of the spectra are similar in all the molecules. Unfortunately some limitations in the experimental data limit the theoretical significance of the results. On theoretical grounds, with chemically similar molecules of this type, one would expect the total ionization at constant pressure to be nearly proportional to the molecular weight $[6,7]$. 
The total ion current cannot be accurately evaluated. The sum of all the measured peaks in tetraphenyl was 1.67 times the molecule ion peak, in hexaphenyl the ratio was 1.76 and in octaphenyl 1.38. These are lower limits as many little peaks were omitted and the sum of these is not negligible. In spectra obtained with a Consolidated mass spectrometer and heated inlet system the sum of the measured peaks in terphenyl, tetraphenyl, and hexaphenyl was about 2 relative to the molecule ion peak. In pentaphenyl the sum was 1.6 but the data are incomplete. Part of the difference between measurements with the two instruments comes from mass discrimination in the Consolidated mass spectrometer. It is concluded that the ratio of the molecule ion current to the total ion current remains roughly the same with the possible exception of octaphenyl.

There is a large isotope correction in these heavy molecules for molecules containing $\mathrm{C}^{13}$ and D. For terphenyl the abundance of $\mathrm{C}_{18}^{12} \mathrm{H}_{14}^{1}$ is 0.816 times the monoisotopic abundance of $\mathrm{C}_{18} \mathrm{H}_{14}$ and for octaphenyl, $\mathrm{C}_{48} \mathrm{H}_{34}$, the factor is 0.582 . The reciprocal of this fraction is the correction factor to be applied to the $\mathrm{C}_{n}^{12} \mathrm{H}_{m}^{1}$ peak to give the monoisotopic abundance. The 6 th and 7 th columns of table 2 give the correction factor and the monoisotopic relative sensitivity.

The resolving power of the mass spectrometer is about $1 / 300$ and is insufficient to resolve unit mass for the hexaphenyl and octaphenyl ions. For octaphenyl the peaks at 610 and 611 will be completely unresolved and there can be a large error in evaluating the abundance of 610 . For hexaphenyl the error is much less.

It is noted above that theory indicates that the effective collision area for ionization of polyphenyls will be proportional to the molecular weight. The relative sensitivity increases much more rapidly than this. Thus the ratio of the monoisotopic sensitivity of octaphenyl to that of terphenyl is 5.76 while the molecular weight ratio is 2.66 . The experimental ratio is considered to be more reliable for tetraphenyl and octaphenyl. Here the sensitivity ratio is 3.1 and the molecular weight ratio is 2 . The experimental uncertainties cannot account for this large increase in sensitivity with molecular weight.

These preliminary results are published because the experimental work has been interrupted and there is no immediate prospect of getting more accurate data. Results are of some interest as they afford the only experimental data on the sensitivity of mass spectrometers of this type for heavy molecules. The change in sensitivity with molecular weight is in marked contrast to data obtained with instruments operating at constant magnetic field. The API Catalog of mass spectral data gives sensitivities for some fused ring aromatics [8] and in these spectra also the molecule ion is the only large peak. For isomers of $\mathrm{C}_{16} \mathrm{H}_{10}$ (mass 202) the sensitivity is 56 times that for the molecule ion of hexadecane; for $\mathrm{C}_{18} \mathrm{H}_{12}$ isomers (mass 228) sensitivity ratios range from 23 to 12 ; for $\mathrm{C}_{20} \mathrm{H}_{12}$ (mass 252 ) the ratio is 26 , and for $\mathrm{C}_{22} \mathrm{H}_{14}$ the ratio is 19. The sensitivity per micron shows the same unsystematic variation.

\section{References}

[1] Paul Bradt, V. H. Dibeler, and F. L. Mohler, J. Research NBS 50,201 (1953) RP2410.

[2] Paul Bradt and F. L. Mohler, Anal. Chem. 27, 875 (1955).

[3] Paul Bradt and F. L. Mohler, J. Research NBS 55, 323 (1955) RP2637.

[4] Paul Bradt, F. L. Mohler, and V. H. Dibeler, J. Research NBS 5\%, 223 (1956) RP2713.

[5] Preston P. Morris, Jr. (unpublished research).

[6] J. W. Otvos and D. P. Stevenson, J. Am. Chem. Soc. 78, 546 (1956).

[7] F. W. Lampe, J. L. Franklin, and F. H. Field, J. Am. Chem. Soc. 79, 6129 (1957).

[8] API Catalog of Mass Speetral Data; Serial Numbers $958,959,1017,1018,1019,1020,1022$, and 1237 .

Washington, July 31, 1957. 